\title{
Detached-Leaf Bioassay for Evaluating Taro Resistance to Phytophthora colocasiae
}

\author{
F. E. Brooks, Community and Natural Resources Division, American Samoa Community College, Pago Pago, AS \\ 96799
}

\begin{abstract}
Brooks, F. E. 2008. Detached-leaf bioassay for evaluating taro resistance to Phytophthora colocasiae. Plant Dis. 92:126-131.

Taro leaf blight disease, caused by Phytophthora colocasiae, is a major limiting factor in taro production worldwide. P. colocasiae is an aerial pathogen similar to P. infestans, causal agent of potato late blight disease, but occurs in warmer climates. In the year-round subsistence cropping systems of the Pacific Islands, resistant cultivars are essential. Breeding lines from Southeast Asia and Oceania were tested in American Samoa for resistance to taro leaf blight using a detached-leaf bioassay and field trials. Mean lesion diameters from bioassays were highly correlated with field estimates of the number of healthy leaves per plant and yield (corm weight). However, the bioassay did not adequately assess infection efficiency. Additional experiments revealed that attached leaves had smaller lesion diameters than detached leaves incubated in closed containers, but both were very highly correlated. Taro resistance increased with plant age and the second-oldest leaf was more resistant than the third-oldest leaf. The bioassay was a fast, space-saving, effective method of screening taro lines for post-penetration resistance to P. colocasiae. It also provided an easily standardized method of evaluating host-pathogen interactions under controlled conditions.
\end{abstract}

Additional keywords: Colocasia esculenta, Samoan Archipelago

Leaf blight of taro, Colocasia esculenta (L.) Schott., caused by Phytophthora colocasiae Racib., limits taro production throughout the tropics and is often of great cultural significance, especially in Southeast Asia and the Pacific Islands $(6,10,22)$. Taro leaf blight (TLB) is mainly a foliar disease, similar to late blight of potato (7), but occurs under warmer conditions (40), and inoculum is always available due to continuous cropping. $P$. colocasiae grows from 15 to $35^{\circ} \mathrm{C}(12)$, with an optimum of 27 to $30^{\circ} \mathrm{C}$ (18). Epidemics are favored by repeated nighttime temperatures close to $20^{\circ} \mathrm{C}$ and relative humidity of 90 to $100 \%$ when zoospore release is greatest $(39,40)$. Visible lesions appear 2 to 4 days after inoculation (3) and, under humid conditions, can destroy large taro leaves with a 30- to 40-day lifespan in 5 to 10 days $(20,32)$. Yield losses may reach 50 to $60 \%$ under severe blight conditions $(1,20)$ and susceptible taro cultivars can be destroyed completely.

TLB first was reported in the Samoan Archipelago in $1993(35,42)$. Niue was the

Corresponding author: F. Brooks

E-mail: fredbrooks@hotmail.com

This work was funded by United States Department of Agriculture (CSREES) grant no. 0201093 and no. 0198937.

Accepted for publication 20 August 2007.

doi:10.1094/PDIS-92-1-0126

(C) 2008 The American Phytopathological Society favored cultivar at the time, comprising over $75 \%$ of an estimated US $\$ 10$ million in annual exports for (Western) Samoa (17) and most of the $357,000 \mathrm{~kg}$ grown for local use in American Samoa (2). By 1995, the TLB epidemic had decimated the susceptible cv. Niue, reducing Samoa's export market to US\$60,750 and American Samoan production to a reported $5,000 \mathrm{~kg}$.

In 2005, the Land Grant division of American Samoa Community College began importing new hybrids with putative general resistance to TLB with the goal of protecting taro production in the territory by increasing its genetic diversity $(6,22,24)$. However, field evaluations of TLB require time, labor, and space and the results are subject to variations in weather (40), isolate virulence (23), disease pressure (46), and assessment method (7). Researchers working with other Phytophthora spp. have addressed these limitations by developing laboratory or greenhouse bioassays for rapid testing of host resistance $(9,15,19,26,29,31,34,36)$. However, near-vertical leaves with hydrophobic surfaces $(32,40)$ present an additional obstacle to taro bioassays, especially when small drops of inoculum are applied (34).

In 1998, Xu and Ko (47) published an effective method of quantifying swimming spores, applying small numbers of propagules to plant surfaces, and fixing them in place. This article describes an adaptation of their technique (47) to a detached-leaf bioassay for screening taro resistance to $P$. colocasiae. Several elements of the host-pathogen interaction were evaluated in order to standardize the bioassay, which then was validated by comparison with field trials.

\section{MATERIALS AND METHODS}

Plant material. Taro lines (hybrids) with putative resistance to TLB were imported from breeding programs in Southeast Asia and Oceania through the Secretariat of the Pacific Community's Regional Germplasm Centre in Suva, Fiji (Table 1). Plantlets were multiplied in our tissue culture facility on Murashige and Skoog (MS) medium with sucrose at $30 \mathrm{~g} \mathrm{liter}^{-1}$ and thidiazuron (TDZ) at $0.5 \mathrm{mg} \mathrm{liter}^{-1}$ and then transferred to MS plus sucrose at $20 \mathrm{~g} \mathrm{liter}^{-1}$ for root formation. Rooted plantlets of each hybrid were potted in a sterile, soilless mix with slow-release fertilizer (14-14-14 Osmocote; Scott's Miracle-Gro Co., Marysville, $\mathrm{OH}$ ) and tested at least three times with the bioassay while in the greenhouse. Because leaves from hybrids growing in field experiments were part of routine assessments, field-hardened leaves from their suckers were tested in the laboratory for comparison.

Inoculum. $P$. colocasiae isolate PC114 from a taro plot at the Land Grant Station in Malaeimi, Tutuila Island, was used for all assessments. Cultures were grown on modified V8 juice agar $(150 \mathrm{ml}$ of V8 juice, $3.0 \mathrm{~g}$ of $\mathrm{CaCO}_{3}, 0.03 \mathrm{~g}$ of thiamine, $15 \mathrm{~g}$ of agar, and distilled water to 1 liter; 10) and incubated at $24^{\circ} \mathrm{C}$ with fluorescent light at $10 \mathrm{~h} \mathrm{day}{ }^{-1}$. Sterile distilled water was added to 5- to 10-day-old cultures before chilling at $10^{\circ} \mathrm{C}$ for $30 \mathrm{~min}$ to stimulate zoospore release from zoosporangia. The spore concentration was diluted about 15 min after chilling until $1-\mu l$ drops viewed under a stereomicroscope contained an average of five to seven zoospores each. Adjusting a micropipette to deliver 50 zoospores produced drops of 7 to $10 \mu \mathrm{l}$; smaller drops adhered to the pipette tip due to capillarity.

Bioassay. The second- or third-oldest leaves of taro plants at least 30 days old were removed just below the blade and the upper surface gently wiped with a tissue (Kimwipes, Kimberly-Clark, Dallas). Two to three drops of inoculum, each containing 50 zoospores, were applied to each side of the leaf with sterile distilled water as a control. In a modification of $\mathrm{Xu}$ and Ko's method (47), each inoculation was covered with a $20-\mu 1$ drop of molten water agar $\left(45\right.$ to $50^{\circ} \mathrm{C}$ ) to fix the inoculum in place and help prevent desiccation. Sites were marked with a felt pen. Inoculated 
leaves of each hybrid were laid on moist paper towels in covered plastic containers located at random on a laboratory bench and incubated at $24^{\circ} \mathrm{C}$ and ambient light. At a laboratory temperature of $24^{\circ} \mathrm{C}$, average leaf sizes of 15 by $25 \mathrm{~cm}$ allowed four to six lesions per leaf to expand and still be measurable up to 5 days after inoculation. At 6 days, lesions often coalesced or were difficult to read due to deteriorating leaf tissue.

Two components of polygenic or general resistance were evaluated with the bioassay. Infection efficiency (IE; 4,43), or penetration resistance (19), was calculated for each hybrid by dividing the number of positive infections by the total number of inoculations. The near-circular lesions produced by this inoculation method were measured daily from day 2 , when symptoms first appeared, until day 5 by averaging two diameters made at right angles to each other. The mean lesion diameter (MLD) for each hybrid was recorded at day 5. Lesion growth rate $\left(\mathrm{mm} \mathrm{day}^{-1}\right)$ was determined for all cultivars and hybrids, but because of its similarity to MLD and their high correlation $(r=0.924, P$ $>0.001$ ), only MLD is reported in this article. IE was compared between hybrids with two-way analysis of variance (ANOVA) and $z$ tests, whereas MLDs were compared by one-way ANOVA. At the end of each experiment, $P$. colocasiae was reisolated and transferred to V8 juice agar for the next trial. All experiments were repeated at least twice.

Comparison of bioassay with field results. In 2006, replicated field experiments were planted in Pava'ia'i and Malaeimi within $3 \mathrm{~km}$ of each other on the main island of Tutuila, American Samoa. A third, nonreplicated field trial was planted in Tafeta in 2006-07 on a cool, wet ridgeline known for its severe blight conditions. Samoan farmers used traditional farming practices to plant and maintain the plots: no fertilizer, pesticides, or supplemental water were applied during the trials. Plant height, number of leaves, and disease severity were estimated biweekly in Pava'ia'i and Malaeimi and weekly in Tafeta from week 5 until harvest at week 24. TLB severity was estimated for each plant leaf in increments of 1 (first early lesion), 5, 10, 25, 50, 75, 95, and 100\%. The number of healthy leaves per plant was determined by deducting the percent blighted tissue $(100 \%=$ one leaf $)$ from the average number of leaves per plant. Area under the disease progress curve (AUDPC) was calculated for each hybrid, then normalized by dividing it by the total area of the graph (11). MLD and IE from bioassays were compared with all field measurements using Spearman rank order correlation (SigmaStat; Systat Software, Inc., San Jose, CA). No pesticide-protected controls were planted and no baseline data were available for the breeding lines.

Factors tested to standardize the bioassay included (i) plant age, (ii) leaf age, (iii) attached versus detached leaves, (iv) leaf surface treatment, (v) wounding, (vi) spore concentration, and (vii) upper versus lower leaf surface inoculation.

Plant age. During early bioassays, inoculated leaves of all hybrids showed a decrease in lesion diameter with increasing plant age. To verify this observation, leaves were collected from greenhouse- and fieldgrown hybrids during 2006-07, inoculated, and MLDs compared with plant age by linear regression (SigmaPlot; Systat Software, Inc.).

Leaf age (position). Laboratory and field observations that the second-oldest taro leaves were more resistant to TLB than the third-oldest were evaluated by measuring IE and MLD as part of the attached versus detached leaves experiments (see below).

Attached versus detached leaves. Four experiments were conducted to measure the effect on IE and MLD of removing leaves from plants (45). Breeding lines MH24 and MH40 each were tested once and IND245 was tested twice. In each experiment, the attached second- and thirdoldest leaves of four plants were wiped individually with a tissue, supported horizontally on a ring stand, and inoculated using the bioassay protocol. Relative humidity was kept at $85 \%$ by incubating the plants on wet paper towels in sealed black plastic trash bags for $48 \mathrm{~h}$. After 2 days, the black bags were removed, lesions measured, and clear plastic bags suspended over the plants to maintain $75 \%$ relative humidity until the end of the experiment. In all, 10 detached second leaves and 10 detached third leaves from the same hybrid also were inoculated, incubated at $85 \%$ relative humidity in closed plastic containers, and evaluated daily.

Leaf surface treatment. One of the main obstacles to inoculating taro leaves is their hydrophobic surface $(14,41)$. Treating the surface with alcohol and rinsing it thoroughly was successful but time-

Table 1. Components of resistance of taro hybrids to Phytophthora colocasiae as measured in a bioassay (MLD and IE) and in three field trials (Leaves, AUDPC, and Corm) $)^{\mathrm{y}}$

\begin{tabular}{|c|c|c|c|c|c|c|c|}
\hline Hybrid & Country & Resistance $^{\mathrm{z}}$ & $\operatorname{MLD}(\mathbf{m m})$ & IE (\%) & Leaves & AUDPC & Corm \\
\hline Dalo ni Jaina & Fiji & NI & 48.9 & 98 & 1.7 & 0.47 & 24.8 \\
\hline Uro ni Vonu & Fiji & NI & 50.3 & 99 & 2.6 & 0.35 & 78.2 \\
\hline MH24 & Hawaii & $\mathrm{T}$ & 43.8 & 96 & $\ldots$ & $\ldots$ & $\ldots$ \\
\hline MH40 & Hawaii & $\mathrm{T}$ & 46.2 & 96 & 3.0 & 0.07 & 149.6 \\
\hline IND218 & Indonesia & $\mathrm{T}$ & 48.5 & 100 & $\ldots$ & $\ldots$ & $\ldots$ \\
\hline IND245 & Indonesia & $\mathrm{T}$ & 43.7 & 92 & $\ldots$ & $\ldots$ & $\ldots$ \\
\hline IND399 & Indonesia & $\mathrm{T}$ & 39.4 & 100 & $\ldots$ & $\ldots$ & $\ldots$ \\
\hline IND400 & Indonesia & $\mathrm{T}$ & 51.5 & 89 & 3.4 & 0.35 & 88.5 \\
\hline IND472 & Indonesia & $\mathrm{T}$ & 48.0 & 98 & 2.3 & 0.25 & 45.5 \\
\hline MAL136 & Malaysia & $\mathrm{R}$ & 44.6 & 92 & $\ldots$ & $\ldots$ & \\
\hline MAL141 & Malaysia & $\mathrm{R}$ & 38.2 & 98 & 3.8 & 0.06 & 195.7 \\
\hline MAL142 & Malaysia & I & 42.3 & 89 & 2.6 & 0.09 & 77.6 \\
\hline MAL144 & Malaysia & I & 45.1 & 96 & 2.5 & 0.33 & 80.0 \\
\hline MAL148 & Malaysia & $\mathrm{R}$ & 38.4 & 91 & 3.4 & 0.28 & 169.7 \\
\hline PH057 & Philippines & $\mathrm{T}$ & 41.2 & 100 & 3.1 & 0.37 & 127.7 \\
\hline PH157 & Philippines & $\mathrm{T}$ & 43.2 & 97 & 3.4 & 0.36 & 187.4 \\
\hline PH038 & Philippines & $\mathrm{T}$ & 49.7 & 96 & 3.3 & 0.22 & 85.9 \\
\hline C2-E3 & Papua New Guinea & $\mathrm{R}$ & 50.7 & 100 & 2.1 & 0.33 & 75.6 \\
\hline C2-TIP11 & Samoa & $\mathrm{T}$ & 40.4 & 98 & 4.2 & 0.38 & 383.4 \\
\hline C3-194 & Samoa & $\mathrm{T}$ & 45.6 & 94 & $\ldots$ & $\ldots$ & 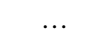 \\
\hline THA138 & Thailand & $\mathrm{S}$ & 57.7 & 99 & 1.7 & 0.40 & 24.9 \\
\hline VN044 & Vietnam & $\mathrm{T}$ & 54.2 & 96 & 1.6 & 0.55 & 19.1 \\
\hline VAN268 & Vanuatu & NI & 54.4 & 98 & 2.1 & 0.37 & 111.7 \\
\hline
\end{tabular}

${ }^{y}$ MLD $=$ mean lesion diameter at 5 days, IE $=$ infection efficiency, Leaves $=$ average number of healthy leaves; AUDPC $=$ area under the disease progress curve (normalized, see text), Corm $=$ corm weight $(\mathrm{g})$, and $\ldots=$ hybrid tested in the laboratory and mentioned in the text, but no field data is available.

${ }^{\mathrm{z}}$ Level of hybrid resistance to taro leaf blight disease reported by each country. $\mathrm{NI}=$ no information, $\mathrm{T}=$ tolerant, $\mathrm{R}=$ resistant, $\mathrm{I}=\mathrm{immune}$, and $\mathrm{S}=$ susceptible. 
consuming. The inoculum also spread across the leaf surface, reducing the effectiveness of water agar cover drops and lesion measurements. Wiping the leaf surface gently with a tissue was fast and effective; therefore, it was tested for possible influences on IE and MLD. One side of the upper leaf surface of each of five large leaves collected from three locally grown cultivars (Niue, Seve, and Alafua Sunrise) was wiped with a tissue (Kimwipes) before inoculation. The other side of the leaves was not wiped. Five inoculations of 50 zoospores each were applied to each side of the leaf. In three subsequent experiments, five greenhouse-grown hybrids (MAL136, MAL141, IND218, IND399, and IND400) were tested with the same procedure. Because of their smaller leaves, the upper surface of three leaves per hybrid were wiped and three were left unwiped as a control. Only four inoculations were made, two on each side of each leaf.

Wounding. Inoculating leaves with a micropipette can damage their surface and may affect IE and other assessments. To test this assumption, two experiments with five leaves each of field-grown cvs. Ngeruuch (Palau), Seve (Samoa), and Rota
(Guam) and two experiments with five leaves of the greenhouse-grown hybrids used in the leaf-surface-treatment study were tested for the effects of wounding. In the first two experiments, five sites on one side of the cultivars' leaves were wounded with the pipette tip during inoculation. In the second two experiments, two sites on one side of the hybrids' smaller leaves were inoculated. Wounding of the inoculation sites was carefully avoided on the opposite side of the same leaves. The standard bioassay protocol was followed in all other respects. A Student's $t$ test was used to detect differences between MLDs for wounded and nonwounded leaves in each trial.

Spore concentration. Zoospores were chosen for the bioassay for two reasons. First, they were easier to quantify than zoosporangia, which either germinate directly as one spore or indirectly by releasing 8 to 10 zoospores. Second, zoospores are the most common source of infection in the field $(28,40)$. Five experiments were conducted to find the lowest concentration of zoospores that would consistently produce lesions. In the first two experiments, inoculum was adjusted to 6 to 25 zoospores $\mu \mathrm{l}^{-1}$ and the micropipette calibrated

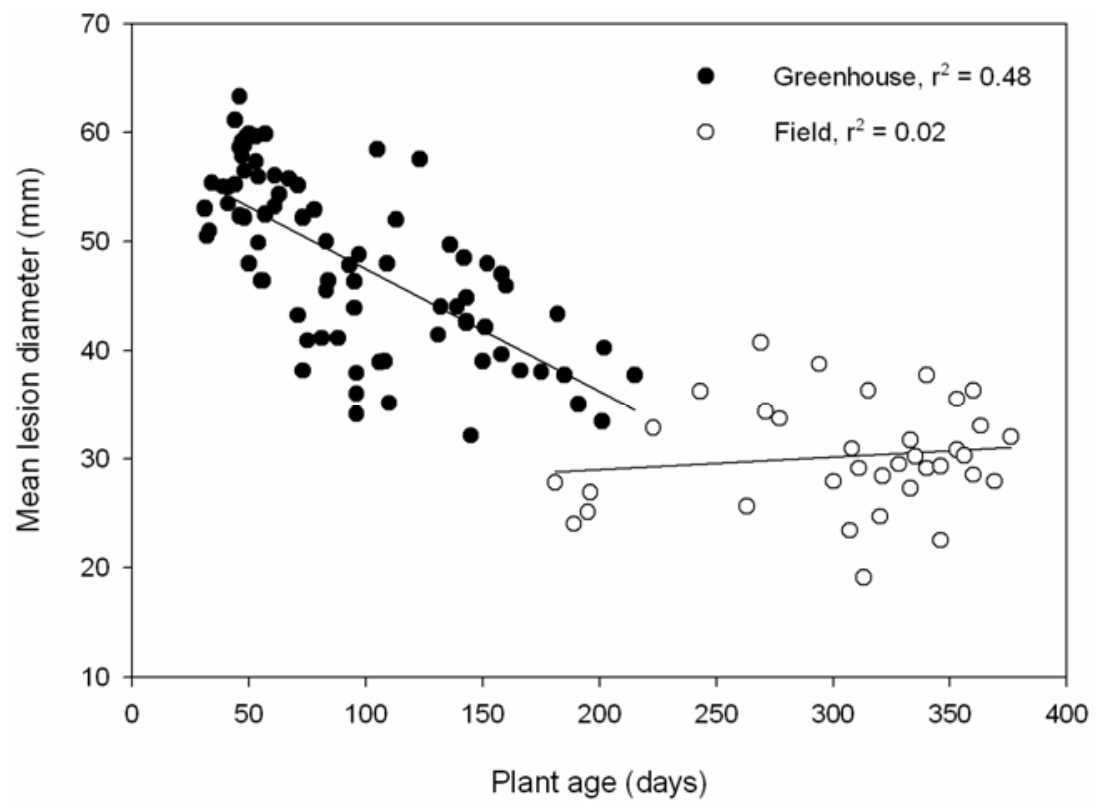

Fig. 1. Effect of increasing plant age on mean lesion diameter for greenhouse- and field-grown taro hybrids with putative resistance to taro leaf blight disease $(P<0.01)$. Each data point represents 20 laboratory inoculations. to deliver 50,100 , or 250 zoospores. In the final three experiments, the same procedure was followed, but with inoculum concentrations of 2 to 7 zoospores $\mu \mathrm{l}^{-1}$ and the micropipette calibrated to deliver 15 , 30 , or 50 zoospores. Six leaves from resistant taro cv. Ngeruuch (Palau) were collected from the field for each experiment. Nine inoculations, three each of the three zoospore concentrations, plus a water control were placed at random on each leaf and identified with a felt pen.

Upper versus lower leaf surface inoculation. The newest leaf in both taro and banana is a tightly rolled cylinder emerging from the center of the plant. The lower leaf surface faces outward and, in banana, is the inoculation site for Mycosphaerella fijiensis, the cause of black leaf streak disease, or black Sigatoka (27). To compare the susceptibility of upper and lower leaf surfaces of taro to $P$. colocasiae, three experiments were conducted on four different hybrids: Uro ni Vonu, PH038, C3194, and IND400. Four inoculations were made on the lower leaf surface of each of five leaves per hybrid in each experiment. The procedure was repeated for the upper leaf surface of five different leaves per experiment. Two-way ANOVA was used to compare IEs on upper and lower leaf surfaces and interactions between IE and MLD. MLD between hybrids was evaluated by ANOVA on ranks and pairwise separation of means.

\section{RESULTS}

Plant age. MLD on leaves of all hybrids growing in the greenhouse decreased with increasing plant age (Fig. 1). Plant ages were between 31 and 215 days for hybrids from the greenhouse and 181 to 376 days for leaves from plants growing in the field. The increase in resistance to TLB occurred in the younger greenhouse-grown plants only $\left(r^{2}=0.48\right)$, not in older field-grown plants $\left(r^{2}=0.02\right)(P<0.01)$. Sterile water controls were negative in all experiments.

Leaf age (position). The third leaves of greenhouse-grown hybrids in all but the first experiment conducted in 2007 had larger MLDs after 5 days than second leaves (Table 2). There was no significant difference in IE $(P=0.460)$.

Attached versus detached leaves. The average MLD for all experiments on leaves detached from plants and incubated in

Table 2. Differences in mean lesion diameter at 5 days (MLD) and infection efficiency (IE) for the second- and third-oldest leaves, attached and detached, of three taro hybrids: MH24, MH40 and IND245z

\begin{tabular}{|c|c|c|c|c|c|c|c|c|}
\hline \multirow[b]{3}{*}{ Experiment } & \multicolumn{4}{|c|}{ Attached leaves } & \multicolumn{4}{|c|}{ Detached leaves } \\
\hline & \multicolumn{2}{|c|}{ Second leaf } & \multicolumn{2}{|c|}{ Third leaf } & \multicolumn{2}{|c|}{ Second leaf } & \multicolumn{2}{|c|}{ Third leaf } \\
\hline & $\operatorname{MLD}(\mathbf{m m})$ & IE (\%) & $\operatorname{MLD}(\mathbf{m m})$ & IE (\%) & $\operatorname{MLD}(\mathbf{m m})$ & IE (\%) & $\operatorname{MLD}(\mathbf{m m})$ & IE (\%) \\
\hline 1. MH24 & 35.3 & 95 & 35.2 & 80 & 39.4 & 92.5 & 39.5 & 95 \\
\hline 2. MH40 & 28.5 & 100 & 26.0 & 100 & $38.7 *$ & 90 & $41.5^{*}$ & 95 \\
\hline 3. IND245 & $34.0^{*}$ & 63 & $39.8^{*}$ & 88 & $41.1 *$ & 90 & $44.9^{*}$ & 75 \\
\hline 4. IND245 & $37.6^{*}$ & 88 & $42.3^{*}$ & 88 & $40.6^{*}$ & 75 & $42.7^{*}$ & 90 \\
\hline
\end{tabular}

${ }^{\mathrm{z}}$ An asterisk $(*)$ indicates differences in MLD between second and third leaves in the same experiment $(P<0.05)$. 
closed containers (41 mm) was significantly greater $(P<0.001)$ than for leaves still attached to plants $(35.5 \mathrm{~mm})$ (Table $2)$. The correlation between MLDs on attached and detached leaves for the four trials combined, however, was high ( $r=$ 0.956, $P<0.0001)$. Differences in IE were not significant $(P=0.847)$.

Leaf surface treatment. There was no significant difference in MLD between wiped and unwiped leaf surfaces for the same cultivar or hybrid, though there were differences in MLD among cultivars and hybrids. There was no significant difference in IE $(P=0.947)$ between treatments.

Wounding. Wounding the leaf surfaces of field-grown taro cultivars and greenhouse-grown hybrids did not affect MLD or IE in these experiments (Table 3). There were significant differences among some cultivars and hybrids for lesion growth $(P$ $<0.05$ ); however, the average differences in MLDs between wounded and nonwounded leaves for all trials was not significant $(P=0.615)$.

Spore concentration. MLD increased with increasing spore concentration (Table 4). MLDs from inoculations with 150 and 250 zoospores were significantly greater $(P<0.001)$ than from inoculations with 15 and 30 zoospores. IE between 15 and 30 zoospores was significant at $P<0.01$.

Upper versus lower leaf surface inoculation. Inoculation of the upper or lower leaf surface had no effect on IE ( $P=$ 0.146 ), even allowing for differences in cultivars. MLD was significantly higher for hybrid IND400 $(P<0.001)$ than for C3-194, PH038, or Uro ni Vonu, but was not correlated with inoculation site $(P=$ 0.215).

Comparison of bioassay with field results. A comparison of hybrids tested in the laboratory (Table 1) showed no correlation between IE and any other variable (Table 5). However, there were significant negative correlations between MLD and the average number of healthy leaves per plant and yield (corm weight). The medium correlation between MLD and AUDPC, 0.444 , was not significant $(P=$ 0.07). Among field assessments, yield was more strongly correlated with leaf number (data not presented) and the number of healthy leaves per plant than with AUDPC or plant height. In the Tafeta trial, THA138, Dalo ni Jaina, and VN044 were severely damaged by blight conditions,

Table 3. Mean lesion diameter at 5 days (MLD) and infection efficiency (IE) for wounded and nonwounded leaves of field-grown cultivars and greenhouse-grown hybrids ${ }^{\mathrm{z}}$

\begin{tabular}{lccccc}
\hline & \multicolumn{2}{c}{ Wounded } & & \multicolumn{2}{c}{ Nonwounded } \\
\cline { 2 - 3 } \cline { 5 - 6 } Experiment & MLD (mm) & IE (\%) & & MLD (mm) & IE (\%) \\
\hline Cultivars 1 & 36.0 & 97 & & 35.0 & 100 \\
Cultivars 2 & 36.5 & 97 & & 36.0 & 100 \\
Hybrids 1 & 44.0 & 87 & & 45.0 & 83 \\
Hybrids 2 & 46.5 & 100 & & 44.0 & 95 \\
\hline
\end{tabular}

${ }^{\mathrm{z}}$ Differences in treatments were not significant at $P=0.05$. with an average height over the 6-month trial of $16 \mathrm{~cm}$. Their average height at harvest was $10 \mathrm{~cm}$, corm weight $23 \mathrm{~g}$, and $18 \%(11 / 60)$ of the plants were not visible aboveground. In the same trial, Uro ni Vonu and VAN268, with an MLD in the laboratory similar to the damaged hybrids, had average heights of 52.6 and $63.1 \mathrm{~cm}$ and corm weights of 78.2 and $111.7 \mathrm{~g}$, respectively.

\section{DISCUSSION}

The detached-leaf bioassay provided a compact, relatively fast, reliable assessment of taro resistance to $P$. colocasiae and offers early screening for breeding programs with simple laboratory facilities. Successful assays of polygenic resistance using detached leaves or leaf disks also have been reported for $P$. megakarya (30), $P$. palmivora $(19,29,37)$, and $P$. infestans $(26,34,45)$. MLDs measured 5 days after inoculation provided a dependable resistance assessment and were well-correlated with field test estimates of yield, total number of leaves (data not presented), and number of healthy leaves per hybrid (Table $5)$. In an analysis of genotypic and phenotypic components of field resistance to $P$. infestans, Birhman and Singh (4) also concluded that lesion size was the most important factor in breeding for polygenic resistance. For our purposes, however, growth characteristics, corm yield, and eating qualities will still require field experiments.

Resistance estimates provided by breeding programs for their hybrids (Table 1) field results, or both. For example, in the bioassay, IND400 was susceptible, not tolerant, and MAL142 and MAL144 were resistant, not immune. These discrepancies may be due to differences in growing conditions, evaluation methods, or strains of the pathogen.

A relative resistance ranking of the hybrids based on MLD was established as greater than $50 \mathrm{~mm}=$ susceptible, 41 to 50 $\mathrm{mm}=$ moderately resistant, and below 40 $\mathrm{mm}=$ resistant. Selecting rankings was difficult for several reasons. First, only 20 $\mathrm{mm}$ separated the highest and lowest MLDs (Table 1). Second, during early laboratory trials, the importance of certain variables was unknown. Therefore, the results are averages of different-aged plants and a mixture of second and third did not always agree with the bioassay, leaves, both attached and detached. These averaged MLDs also may be part of the discrepancy between bioassay and field results.

Finally, field estimates of TLB based on AUDPC may not correspond to host resistance or be related to yield $(7,8)$. Gollifer and Brown (13) found no correlation between disease severity and yield using a pictorial key to estimate leaf damage but did find a positive correlation between mean number of leaves and yield. Jackson et al. (21) used the same key and determined that yield was best correlated with uninfected leaf area. As with other aerial Phytophthora spp., numerous factors affect disease estimates, including temperature, moisture, and pathogen fitness $(8,11,25)$. Disease progress curves for TLB may be sigmoidal but often are serrated (16), as in our trials (data not presented). According to our findings and supported by Cox (7), this is because TLB is more severe on older leaves. As lesions accumulate during humid conditions, disease estimates quickly rise; then, when heavily diseased leaves collapse, leaving the younger, healthy leaves, disease estimates rapidly decline. Therefore, Cox (7) recommends leaf number as the most relevant measure of yield. In combined data from the Pava'ia'i and Tafeta trials, there was a high correlation between corm weight, leaf number, and the number of healthy leaves per plant. The correlation between the AUDPC and corm weight was low and not significant (Table 5). These results agree with those of Gollifer and Brown (13), Jackson et al. (21), and Cox (7).

Infection efficiency was not adequately tested by the bioassay. There were no significant differences in IE between hybrids or between attached leaves versus detached leaves. The only significant difference in IE was in the spore concentration experiments (Table 4), with fewer positive inoculations from 15 zoospores than from 30 zoospores. Vleeshouwers and coworkers (45) tested the IE and lesion growth rate of $P$. infestans on detached potato leaves in covered and uncovered containers. IE and lesion growth rate for both resistant and susceptible cultivars were consistently higher in covered containers. This suggests that the environment inside covered containers either improved zoospore penetration, enhanced infection, or both. Further,

Table 4. Differences in mean lesion diameter at 5 days (MLD) and infection efficiency (IE) for five zoospore concentrations (Conc.) ${ }^{\mathrm{z}}$

\begin{tabular}{lll}
\hline Conc. & MLD $(\mathbf{m m})$ & IE $(\%)$ \\
\hline 15 & $27.8 \mathrm{a}$ & $81 \mathrm{a}, \mathrm{c}$ \\
30 & $32.8 \mathrm{a}$ & $98 \mathrm{~b}$ \\
50 & $33.7 \mathrm{a}, \mathrm{b}$ & $90 \mathrm{~b}, \mathrm{c}$ \\
150 & $36.0 \mathrm{~b}$ & $92 \mathrm{~b}, \mathrm{c}$ \\
250 & $36.3 \mathrm{~b}$ & $88 \mathrm{~b}, \mathrm{c}$ \\
\hline
\end{tabular}

${ }^{\mathrm{z}}$ MLDs and IEs with different letters are significant at $P<0.001$ and 0.01 , respectively. 
Table 5. Spearman rank order correlation between two laboratory (MLD and IE) and four field (Leaves, AUDPC, Corm wt., and Height) measurements for hybrids tested in 2006-07

\begin{tabular}{lccccc}
\hline Variables & IE & Leaves & AUDPC & Corm wt. & Height \\
\hline MLD & 0.163 & $-0.816^{* * *}$ & 0.444 & $-0.657^{* * *}$ & -0.362 \\
IE & $\ldots$ & -0.188 & 0.337 & -0.113 & 0.119 \\
Leaves & $\ldots$ & $\ldots$ & $-0.484^{*}$ & $0.914^{* * *}$ & $0.606^{* *}$ \\
AUDPC & $\ldots$ & $\ldots$ & $\ldots$ & -0.382 & -0.193 \\
Corm wt. & $\ldots$ & $\ldots$ & $\ldots$ & $\ldots$ & $0.771^{* * *}$ \\
\hline
\end{tabular}

${ }^{\mathrm{z}}$ Combined field data are from 6-month taro leaf blight experiments in Pava'ia'i with mild disease pressure and in Tafeta with severe disease pressure. MLD = mean lesion diameter, IE = infection efficiency, Leaves $=$ healthy leaves, $\mathrm{AUDPC}=$ area under the disease progress curve, Corm wt. = corm weight, Height $=$ plant height; *,**, and $* * *$ indicate $P<0.05,0.01$, and 0.001 , respectively.

fixing inoculum to attached leaves with a drop of water agar in our experiments may have increased IE artificially by protecting zoospores from desiccation. Trujillo (40) demonstrated that zoosporangia plasmolyzed at a relative humidity below $90 \%$. Relative humidity during incubation in our closed containers was $85 \%$ and may have proved lethal to the more fragile zoospores without an agar drop to protect them.

MLDs of greenhouse-grown plants decreased with increasing plant age until about 200 days after planting, when most cultivars are ready for harvest (Fig. 1). These results agree with tests of 181 susceptible and resistant field-grown taro cultivars from the Solomon Islands by Gollifer and Brown (13). At 3 months, $8.8 \%$ of the Solomon Island cultivars had TLB estimates of 51 to $60 \%$, and $0.6 \%$ had 11 to $20 \%$ TLB. After 5 months, however, no cultivars had the high disease rating and $12.2 \%$ were in the 11 to $20 \%$ range. Similarly, Carnegie and Colhoun (5) demonstrated a decreasing IE and lesion growth rate for $P$. infestans on potato leaves prior to flowering, and Phytophthora blight of pepper (Capsicum annuum) caused by $P$. capsici was most severe during the first 5 weeks after planting (33). Visker and colleagues (44) also considered plant age to be a factor in potato late blight resistance, but contended that the increased resistance of apical leaves over basal leaves is the most significant factor in nonspecific (general) resistance to $P$. infestans. Similarly, MLDs in our bioassays were smaller on the second-oldest leaves than on the thirdoldest leaves and Putter (32) reported decreasing levels of resistance to $P$. colocasiae from the first through the fourth leaves of taro. Resistance to P. palmivora on cocoa (Theobroma cacao), however, is highest on older leaves $(29,38)$. Therefore, selecting plants of similar ages and leaves of similar age and position on the plant (44) is important for consistent results in controlled-inoculation studies.

Attached leaves incubated at $75 \%$ relative humidity had significantly smaller MLDs than detached leaves incubated at $85 \%$ relative humidity (Table 2 ), but the correlation between treatments was high. Similar results were reported for attached and detached leaves and pods of cocoa inoculated with $P$. palmivora (19).
Vleeshouwers and others (45) reported that lesion growth on attached leaves and on detached leaves in open containers, both incubated in a moisture chamber, were significantly lower than leaves in closed containers. By further testing, they determined that conditions in closed containers, not leaf detachment itself, were responsible for the higher lesion growth rates.

If sharp micropipette tips scratch or puncture leaf surfaces, they can create entry wounds for pathogens. In a leaf strip thinus) to $P$. palmivora, wounding the leaf surface was needed for reliable disease symptoms (31). In our bioassay, $P$. colocasiae penetrated both upper and lower leaf surfaces equally, creating visible lesions within $48 \mathrm{~h}$ regardless of wounding. Dey and coworkers (9) obtained similar results. Wiping leaf surfaces with a tissue permitted drops of inoculum to release from pipette tips and adhere to the leaf without apparently disrupting leaf surface integrity or affecting MLD or IE.

Leaf inoculations with 50 zoospores consistently produced lesions and provided a predictable number of MLDs for evaluation. IEs were also high, however, and differences in penetration resistance (19) between hybrids were insignificant (Table 1). Lower IEs from inoculations with 15 zoospores were still higher than for other penetration resistance studies that used concentrations between 500 and 12,000 zoospores $(4,19,29,45)$. Under humid field conditions, the only penetration resistance to $P$. colocasiae may be from the waxy cuticle of young taro leaves and their nearvertical position.

In summary, the detached-leaf bioassay was a fast, effective method of screening post-penetration resistance of taro hybrids to $P$. colocasiae. A single measurement of MLD on detached leaves 5 days after inoculation correlated well with yield. To successfully measure IE, the use of open containers placed in a growth chamber with relative humidity $>90 \%$, a lower spore concentration, or omitting the agar cover drop may be necessary. In our laboratory and field experiments, attached leaves were more resistant to $P$. colocasiae than detached leaves and resistance to the pathogen increased with plant age and decreased with leaf age. assay for resistance of durian (Durio zibe-
ACKNOWLEDGMENTS

I thank E. Ilaoa for her assistance, the Secretariat of the Pacific Community's Regional Germplasm Centre in Suva, Fiji, and the breeding programs that unselfishly shared their taro lines.

\section{LITERATURE CITED}

1. Aggarwal, A., and Mehrotra, R. S. 1987. Control of Phytophthora leaf blight of taro (Colocasia esculenta) by fungicides and roguing. Phytoparasitica 15:299-305.

2. Anonymous 1996. American Samoa Statistical Yearbook. Department of Commerce, Statistical Division. American Samoa Government, Pago Pago, AS.

3. Anonymous. 2003. Crop Protection Compendium, 2003 ed. Commonwealth Agricultural Bureaux International, Wallingford, UK.

4. Birhman, R. K., and Singh, B. P. 1995. Pathcoefficient analyses and genetic parameters of the components of field resistance of potatoes to late blight. Ann. Appl. Biol. 127:353-362.

5. Carnegie, S. F., and Colhoun, J. 1982. Susceptibility of potato leaves to Phytophthora infestans in relation to plant age and leaf position. Phytopathol. Z. 104:157-167.

6. Cho, J. J., Yamakawa, R. M., and Hollyer, J. 2007. Hawaiian kalo, past and future. Sustainable Agriculture-1, Cooperative Extension Service, CTAHR, University of Hawaii, Honolulu.

7. Cox, P. G. 1986. Taro leaf blight. Seminar paper presented at Bubia Agricultural Research Centre, Lae, Papua New Guinea.

8. Cox, P. G., and Kasimani, C. 1990. Effect of taro leaf blight on leaf number. Papua New Guinea J. Agric. For. Fish 35:43-48.

9. Dey, T. K., Ali, M. S., Bhuiyan, M. K. R., and Siddique, A. M. 1993. Screening of Colocasia esculenta (L) Schott lines to leaf blight. J. Root Crops 19:62-65.

10. Erwin, D. C., and Ribeiro, O. K. 1996. Phy tophthora Diseases Worldwide. American Phytopathological Society, St. Paul, MN.

11. Fry, W. E. 1978. Quantification of general resistance of potato cultivars and fungicide effects for integrated control of potato late blight. Phytopathology 68:1650-1655.

12. Ghosh, S., Pan, S., and Das, N. 2001. Effect of different media, temperature and humidity on growth and sporangial production of Phytophthora colocasiae Racib. Adv. Plant Sci. 14:279-282.

13. Gollifer, D. E., and Brown, J. F. 1974. Phy tophthora leaf blight of Colocasia esculenta in the British Solomon Islands. Papua New Guinea Agric. J. 25:6-11.

14. Gollifer, D. E., Jackson, G. V. H., and Newhook, F. J. 1980. Survival of inoculum of the leaf blight fungus Phytophthora colocasiae infecting taro, Colocasia esculenta in the Solomon Islands. Ann. Appl. Biol. 94:379-390.

15. Huang, S., Vleeshouwers, V. G. A. A., Visser, R. G. F., and Jacobsen, E. 2005. An accurate in vitro assay for high-throughput disease testing of Phytophthora infestans in potato. Plant Dis. 89:1263-1267.

16. Hunter, D., and Pouono, K. 1998. Evaluation of exotic taro cultivars for resistance to taro leaf blight, yield and quality in Samoa. J. South Pac. Agric. 5:39-43.

17. Hunter, D. G., Iosefa, T., Delp, C. J., and Fonoti, P. 2001. Beyond taro leaf blight: a participatory approach for plant breeding and selection for taro improvement in Samoa. Pages 219-227 in: Proc. Int. Symp. Participatory Plant Breeding and Participatory Plant Genetic Resource Enhancement. Pokhara, Nepal.

18. Ivancic, A., and Lebot, V. 2000. The genetics and breeding of taro. La Librairie du CIRAD, Centre de Cooperation Internationale en $\mathrm{Re}$ cherche Agronomique por le Developpment, Montpellier, France.

19. Iwaro, A. D., Sreenivasan, T. N., and Umaga- 
ran, P. 1997. Foliar resistance to Phytophthora palmivora as an indicator of pod resistance in Theobroma cacao. Plant Dis. 81:619-624.

20. Jackson, G. V. H. 1980. Diseases and Pests of Taro. South Pacific Commission, Noumea, New Caledonia.

21. Jackson, G. V. H., Gollifer, D. E., and Newhook, F. J. 1980. Studies on the taro leaf blight fungus Phytophthora colocasiae in Solomon Islands: control by fungicides and spacing. Ann. Appl. Biol. 96:1-10.

22. Kreike, C. M. van Eck, H. J., and Lebot, V. 2004. Genetic diversity of taro, Colocasia esculenta (L.) Schott, in Southeast Asia and the Pacific. Theor. Appl. Genet. 109:761-768.

23. Lebot, V., Herail, C., Gunua, T., Paradales, J., Prana, M., Thongjiem, M., and Viet, N. 2003. Isozyme and RAPD variation among Phytophthora colocasiae isolates from South-east Asia and the Pacific. Plant Pathol. 52:303-313.

24. Lebot, V., Prana, M. S., Kreike, N., van Heck, H., Pardales, J., Okpul, T., Gendua, T., Thongjiem, M., Hue, H., Viet, N., and Yap, T. C. 2004. Characterisation of taro (Colocasia esculenta (L.) Schott) genetic resources in Southeast Asia and Oceania. Genet. Resour. Crop Evol. 51:381-392.

25. MacKenzie, D. R., Elliott, V. J., Kidney, B. A., King, E. D., Royer, M. H., and Theberge, R. L. 1983. Application of modern approaches to the study of the epidemiology of diseases caused by Phytophthora. Pages 303-313 in: Phytophthora: Its Biology, Taxonomy, Ecology and Pathology. D. C. Erwin, S. BartnickiGarcia, and P. H. Tsao, eds. American Phytopathological Society, St. Paul, MN.

26. Malcolmson, J. F. 1969. Factors involved in resistance to blight (Phytophthora infestans (Mont.) de Bary) in potatoes and assessment of resistance using detached leaves. Ann. Appl. Biol. 64:461-468.

27. Marin, D. H., Romero, R. A., Guzman, M., and Sutton, T. B. 2003. Black Sigatoka: an increasing threat to banana cultivation. Plant Dis. 87:208-222.

28. Mitchell, D. J., and Kannwischer-Mitchell, M. E. 1983. Relationship of inoculum density of Phytophthora species to disease incidence in various hosts. Pages 259-269 in: Phytophthora: Its Biology, Taxonomy, Ecology and Pathology. D. C. Erwin, S. BartnickiGarcia, and P. H. Tsao, eds. American Phytopathological Society, St. Paul, MN.

29. Nyasse, S., Cilas, C., Herail, C., and Blaha, G. 1995. Leaf inoculation as an early screening test for cocoa (Theobroma cacao L.) resistance to Phytophthora black pod disease. Crop Prot. 14:657-663.

30. Nyasse, S., Despreaux, D., and Cilas, C. 2002. Validity of a leaf inoculation test to assess the resistance to Phytophthora megakarya in a cocoa (Theobroma cacao L.) diallel mating design. Euphytica 123:395-399.

31. O'Gara, E., Vawdrey, L., Martin, T., Sangchote, S., van Thanh, H., Bin, L. N., and Guest, D. I. 2004. Screening for resistance to Phytophthora. Pages 194-196 in: Diversity and Management of Phytophthora in Southeast Asia. A. Drenth and D. I. Guest, eds. Australian Centre for International Agricultural Research, Canberra.

32. Putter, C. A. J. 1976. The phenology and epidemiology of Phytophthora colocasiae Racib. on taro in East New Britain Province, Papua New Guinea. M.S. thesis, University of Papua New Guinea, Port Moresby.

33. Reifschneider, F. J. B., Café-Filho, A. C., and Rego, A. M. 1986. Factors affecting expression of resistance in pepper (Capsicum annuum) to blight caused by Phytophthora capsici in screening trials. Plant Pathol. 35:451-456.

34. Sedegui, M., Carroll, R. B., Morehart, A. L., Hamlen, R. A., and Power, R. J. 1999. Comparison of assays for measuring sensitivity of Phytophthora infestans isolates to fungicides. Plant Dis. 83:1167-1169.

35. Semisi, S. T., Mauga, T., and Chan, E. 1998. Control of the leaf blight disease, Phytophthora colocasiae Racib. in taro Colocasiae esculenta (L.) Schott with phosphorous acid. J. South Pac. Agric. 5:77-83.

36. Stewart, H. E. 1990. Effect of plant age and inoculum concentration on expression of major gene resistance to Phytophthora infestans in detached potato leaflets. Mycol. Res. 94:823826.

37. Tahi, G. M., Kebe, B. I., N'Goran, J. A. K., Sangare, A., Mondiel, F., Cilas, C., and Eskes, A. B. 2006. Expected selection efficiency for resistance to cacao pod rot (Phytophthora palmivora) comparing leaf disc inoculations with field observations. Euphytica 149:35-44.

38. Tahi, G. M., Kebe, B. I., Sangare, A., Mondiel, F., Cilas, C., and Eskes, A. B. 2006. Foliar resistance of cacao (Theobroma cacao) to Phytophthora palmivora as an indicator of pod resistance in the field: interaction of cacao genotype, leaf age and duration of incubation. Plant Pathol. 55:776-782.

39. Thankappan, M. 1985. Leaf blight of taro: a review. J. Root Crops 11:1-8.

40. Trujillo, E. E. 1965. The effects of humidity and temperature on Phytophthora blight of taro. Phytopathology 55:183-188.

41. Trujillo, E. E. 1967. Diseases of the genus Colocasia in the Pacific area and their control. Pages 13-19 in: Proc. Int. Symp. Trop. Root Crops, St. Augustine, Trinidad.

42. Trujillo, E. E. 1996. Taro leaf blight research in the American Pacific. ADAP Bull. No. 1, University of Hawaii at Manoa, Honolulu.

43. Umaerus, V., Umaerus, M., Erjefalt, L., and Nilsson, B. A. 1983. Control of Phytophthora by host resistance: problems and progress. Pages 315-326 in: Phytophthora: Its Biology, Taxonomy, Ecology and Pathology. D. C. Erwin, S Bartnicki-Garcia, and P. H. Tsao, eds. American Phytopathological Society, St. Paul, MN.

44. Visker, M. H. P. W., Keizer, L. C. P., Budding, D. J., Van Loon, L. C., Colon, L. T., and Struik, P. C. 2003. Leaf position prevails over plant age and leaf age in reflecting resistance to late blight in potato. Phytopathology 93:666-674

45. Vleeshouwers, V. G. A. A., van Dooijeweert, W., Keizer, L. C. P., Sijpkes, L., Govers, F., and Colon, L. T. 1999. A laboratory assay for Phytophthora infestans resistance in various Solanum species reflects the field situation. Eur. J. Plant Pathol. 105:241-250.

46. Weste, G. 1983. Population dynamics and survival of Phytophthora. Pages 237-257 in: Phytophthora: Its Biology, Taxonomy, Ecology and Pathology. D. C. Erwin, S. BartnickiGarcia, and P. H. Tsao, eds. American Phytopathological Society, St. Paul, MN.

47. Xu, X.-L., and Ko, W.-H. 1998. A quantitative confined inoculation method for studies of pathogenicity of fungi on plants. Bot. Bull. Acad. Sin. 39:187-190. 